\title{
Potentiation of neurite outgrowth and reduction of apoptosis by immunosuppressive agents: implications for neuronal injury and transplantation
}

\author{
Jason Sheehan, M.D., Ph.D., Anne Eischeid, M.S., Randi Saunders, \\ and Nader Pouratian, M.D., Ph.D. \\ Department of Neurological Surgery, University of Virginia Health System, Charlottesville, Virginia
}

\begin{abstract}
Object. Immunosuppressive agents are believed to play a role in recovery from spinal cord injury, but the underlying mechanisms by which neuronal function is improved by these agents are poorly understood. In this study, the authors evaluate the effect of immunosuppressive medications on neurite outgrowth and cell survival after a pharmacologically induced injury.

Methods. Differentiated human neuroblastoma SH-SY5Y cells were injured using the calcium agonist thapsigargin. After cellular injury, neurite outgrowth in the presence or absence of immunosuppressive agents was measured. Apoptosis was quantified with the aid of a terminal deoxynucleotidyl transferase-mediated deoxyuridine triphosphate nick-end labeling assay.

Neurite outgrowth was severely restricted following thapsigargin injury. Outgrowth was potentiated, however, by the addition of concentrations of 1 and $10 \mu \mathrm{M}$ cyclosporin A in a dose-dependent fashion. Similarly, addition of 10 $\mathrm{nM}$ FK506 increased the percentage of neurites in the 20- to 40-micron range. A low dose $(1 \mu \mathrm{M})$ of dexamethasone did not have a significant effect on neurite outgrowth, but a higher dose $(10 \mu \mathrm{M})$ increased the percentage of neurites in the 10- to 45-micron range. These agents also lessened the degree of thapsigargin-induced apoptosis.

Conclusions. Immunosuppressive agents such as cyclosporin A, FK506, and dexamethasone can potentiate neurite outgrowth and protect against apoptotic cell death in a human postmitotic neuronal cell line. Such effects may have implications for lessening neuronal injury after neurotrauma, stroke, or neurodegeneration.
\end{abstract}

KEY WORDS • spinal cord injury • immunosuppressive agent $・$ apoptosis • calcium

$\mathrm{T}$ HE management of severe head or spine injuries currently involves the following three stages: 1) prompt airway and fluid resuscitation following injury; 2) evacuation of any substantial mass lesions (for example, hematoma, bone fragments, or foreign bodies); and 3) adaptive intensive care. Since methylprednisolone was found to benefit patients with acute spinal cord injury, steroid and other immunosuppressive drugs have been the subject of intensive investigation for treatment of neuronal injury. ${ }^{2,4,28}$ Immunosuppressive drugs have also been used to help facilitate graft success following human neuronal transplantation. ${ }^{12,13}$

In recent studies, investigators have demonstrated that calcium perturbations and mitochondrial failure are an important factor in the pathophysiological phenomena leading to neuronal injury after severe trauma. ${ }^{7,16}$ Normally, mitochondria play a major role in the maintenance of intracellular calcium homeostasis. However, when calcium accumulates in the mitochondria after traumatic spinal cord or brain injury, these cell components swell and lose function. ${ }^{26}$ In the presence of free radicals, the mitochondrial

Abbreviations used in this paper: DMEM = Dulbecco modified Eagle medium; PBS = phosphate-buffered saline. permeability transition pore opens, and this leads to cytoplasmic release of calcium, free radicals, and cytochrome C. Such a release can initiate a cascade that causes neuronal injury or even apoptotic cell death. ${ }^{16,23,26}$

Cyclosporin A is believed to exert a neuroprotective effect by blocking the mitochondrial permeability transition pore, inhibiting calcineurin, and thereby preserving mitochondrial function and integrity. ${ }^{7,8}$ Another immunosuppressive drug, FK506, which is used to prevent allograft rejection in organ transplantation, has been shown to inhibit calcineurin, reduce accumulation of intracellular calcium from inositol 1,4,5-trisphosphate-sensitive stores, suppress caspase activation, and protect against apoptosis. $., 6,17$ The other immunosuppressive drug used in this study, dexamethasone, enhances neurotrophin activity and reduces the proapoptotic expression of c-fos and c-jun. ${ }^{14,27}$

To date, little preclinical research has been done to study quantitatively the effects of immunosuppressive agents on human neurite outgrowth after neuronal injury. In this study, we analyze the effects of these agents (that is, FK506, cyclosporin A, and dexamethasone) on the length of neurite outgrowth following pharmacological induction of injury in a human neuronal cell model. ${ }^{19}$ Neurite outgrowth is an important measure of neuronal viability and function. ${ }^{3}$ 


\section{Materials and Methods}

\section{Compounds Used in this Study}

The DMEM, fetal bovine serum, N2 supplement, and penicillinstreptomycin used in this study were obtained from Invitrogen Corp. (Carlsbad, CA). Retinoic acid, ovalbumin, thapsigargin, dexamethasone, and cyclosporin A were obtained from Sigma-Aldrich Chemical Co. (St. Louis, MO). The FK506 was obtained from A.G. Scientific (San Diego, CA).

\section{Cell Culture}

Undifferentiated SH-SY5Y cells (American Type Culture Collection, Manassas, VA) at passage numbers between 93 and 100 were plated in 35-mm glass-bottom dishes (MatTek Corp., Ashland, MA) at densities of between 2 and $4 \times 10^{4}$ cells/dish in high-glucose DMEM supplemented with $10 \%$ fetal bovine serum, $100 \mathrm{U} / \mathrm{ml}$ penicillin, and $100 \mu \mathrm{g} / \mathrm{ml}$ streptomycin. Cells were allowed to grow overnight, then differentiation was started in high-glucose DMEM supplemented with $0.1 \%$ ovalbumin, $1 \% \mathrm{~N} 2$ supplement, $100 \mathrm{U} / \mathrm{ml}$ penicillin, $100 \mu \mathrm{g} / \mathrm{ml}$ streptomycin, and $5 \mu \mathrm{M}$ retinoic acid. ${ }^{19}$ The medium was changed every 2 to 3 days and cells were grown in the differentiation medium for 7 to 10 days before being used for experiments.

\section{Pharmacological Injury}

Differentiated SH-SY5Y cells were stimulated using $100 \mathrm{nM}$ thapsigargin. This pharmacological agent inhibits the sarcoendoplasmic reticular calcium-adenosine triphosphatase pump, causing the release of calcium from the endoplasmic reticulum and thereby increasing the cytosolic levels of calcium. This agent has been used as a trigger for apoptotic cell death and simulates the rise in intracellular calcium levels associated with various types of neuronal injury. ${ }^{10,18}$

\section{Experimental Treatments to Assess Neurite Length}

All treatments were done in differentiation medium. Three 35$\mathrm{mm}$ dishes per condition were pretreated with one of the following agents: $10 \mathrm{nM}$ FK506, $10 \mu \mathrm{M}$ cyclosporin A, $1 \mu \mathrm{M}$ dexamethasone, or $10 \mu \mathrm{M}$ dexamethasone, for 2 hours before the addition of $100 \mathrm{nM}$ thapsigargin. At the specified time after addition of thapsigargin, phase-contrast photomicrographs of the cells were obtained using a Nikon Eclipse TE2000-U microscope (Nikon Instruments, Inc., Melville, NY) equipped with a CoolSnap ES camera (Photometrics, Tucson, AZ; a division of Roper Scientific); a Prior Proscan II (Prior Scientific, Rockland, MA) was used for stage and shutter control. Neurite outgrowth experiments were done in triplicate, and five fields of view from each dish were photographed and evaluated.

\section{Neurite Outgrowth Data Analysis}

Photomicrographs were analyzed for neurite length by using Metamorph software, version 6.1 (Universal Imaging Corp., Downingtown, PA). Cumulative distributions of neurite length were calculated and plotted using Microsoft Excel software (Microsoft Corp., Redmond, WA). Neurite outgrowth was measured and expressed according to previously validated techniques. ${ }^{3}$

Statistical Analysis was performed using StatView software (SAS Institute, Cary, NC). Statistical significance was defined as a probability value less than or equal to 0.05 .

\section{Assay for Apoptotic Cell Death}

To determine whether thapsigargin-induced apoptosis of SHSY5Y cells could be reversed by immunosuppressive agents, a simple terminal deoxynucleotidyl transferase-mediated deoxyuridine triphosphate nick-end labeling assay was performed. The differentiated SHSY5Y cells in 35-mm glass-bottom dishes were removed from their medium and three dishes per condition were pretreated for 2 hours with one of the following immunosuppressive agents: either $1 \mu \mathrm{M}$ cyclosporin A or $20 \mu \mathrm{M}$ dexamethasone. After pretreatment, $100 \mathrm{nM}$ of thapsigargin was added to each dish. Three dishes were left as untreated controls and in three more only thapsigargin was added as another control. (The addition of thapsigargin was regarded as Time 0 for imaging.)

The dishes were removed at the appropriate time point (after 24, 30,36 , or 48 hours) and washed with 1x PBS. For all washing and fixation steps, we used 1 to $2 \mathrm{ml}$ of solution per dish. The cells were then fixed with $3.7 \%$ paraformaldehyde in $10 \%$ buffered formalin PBS for 10 minutes. Postfixation was then performed by adding $100 \%$ methanol to each dish for 20 minutes. Next, $80 \%$ ethanol was added for 10 minutes, and then the cells were air-dried for $10 \mathrm{~min}$ utes. After that, $70 \%$ ethanol was added to the cells for 10 minutes, and the postfixation protocol was concluded by allowing the cells to air-dry overnight. These fixed cells could then be stored at $4^{\circ} \mathrm{C}$ until they were needed for apoptosis staining. The cells needed to be rehydrated to perform the apoptosis staining protocol, and an ethanol series of 100,95 , and $70 \%$ ethanol, with each addition followed by 1x PBS for 5 minutes, was used for rehydration.

The apoptosis staining was begun by washing the cells for 5 minutes with 1 to $2 \mathrm{ml}$ of $1 \mathrm{x}$ PBS per dish. The cells were then permeabilized with $0.1 \%$ Triton X-100 in PBS (100 $\mu 1$ per dish) for 15 minutes. The apoptosis staining was then performed according to the manufacturer's protocol for the ApopTag kit (S7101; Chemicon International, Inc., Temecula, CA). A blue counterstain kit (R \& D Systems, Minneapolis, MN) was then applied to the dishes to allow the total number of cells to be counted more easily. The counterstain, which contains hematoxylin and aniline blue dye in a 1:5 dilution with double-distilled water, was added in 100- $\mu$ l amounts to each dish for 75 to 180 seconds. The dishes were then washed 10 times with tap water and then with ammonium water for 30 seconds. A series of 10 washes each with tap water and then with 70, 95, and finally $100 \%$ ethanol were performed, and the dishes were air-dried and mounted with Permount.

The dishes were analyzed for the fraction of apoptotic cells; under each experimental condition, analyses were performed in triplicate and five fields of view were assessed for the percentage of apoptotic cells. Again, statistical analysis was performed using StatView software; a probability value of less than or equal to 0.05 was deemed significant.

\section{Results}

\section{Response to Cyclosporin A}

Neurite length was enhanced with cyclosporin A in a dose-dependent fashion. At 60 hours after thapsigargininduced injury, $1 \mu \mathrm{M}$ cyclosporin A increased neurite outgrowth over that in thapsigargin-injured cells alone (Fig. 1). The proportion of neurites whose lengths were less than or equal to $30,35,40$, and 45 microns was increased in cells treated with $1 \mu \mathrm{M}$ cyclosporin A in comparison with the proportion in thapsigargin-injured cells that were not treated with an immunosuppressive agent $(\mathrm{p}<0.05$, ttest). Addition of $10 \mu \mathrm{M}$ cyclosporin A dramatically increased neurite lengths; with this treatment, $20 \%$ of neurites had a length of 40 microns or more, compared with $4 \%$ in the cells given thapsigargin alone (Fig. 2).

\section{Response to FK506}

The addition of $10 \mathrm{nM}$ FK506 rescued and increased the fraction of neurites whose lengths were less than or equal to 20,30 , and 40 microns in a statistically significant fashion ( $\mathrm{p}<0.05$, t-test), compared with those of cells treated with thapsigargin alone (Fig. 3).

\section{Response to Dexamethasone}

Pharmacological rescue of neurite length using $1 \mu \mathrm{M}$ dexamethasone worsened the overall distribution of neurite lengths compared with cells treated with thapsigargin 


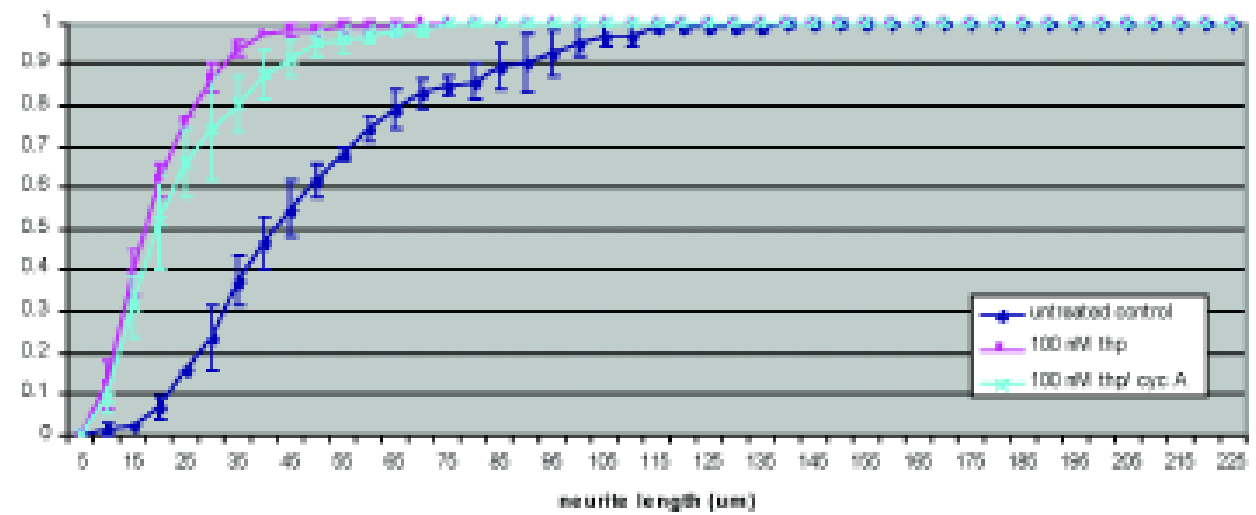

FIG. 1. Graph showing neurite length in cell cultures after a 60-hour incubation with $1 \mu \mathrm{M}$ cyclosporin A (cyc A). Treatment with $100 \mathrm{nM}$ thapsigargin (thp) was used to induce pharmacological injury in the differentiated SH-SY5Y cells. Error bars represent the standard error of the mean; asterisk denotes statistical significance $(\mathrm{p}<0.05)$ in all graphs.

Neurite Length with 10 uM Cyclosporin A after 60 hours

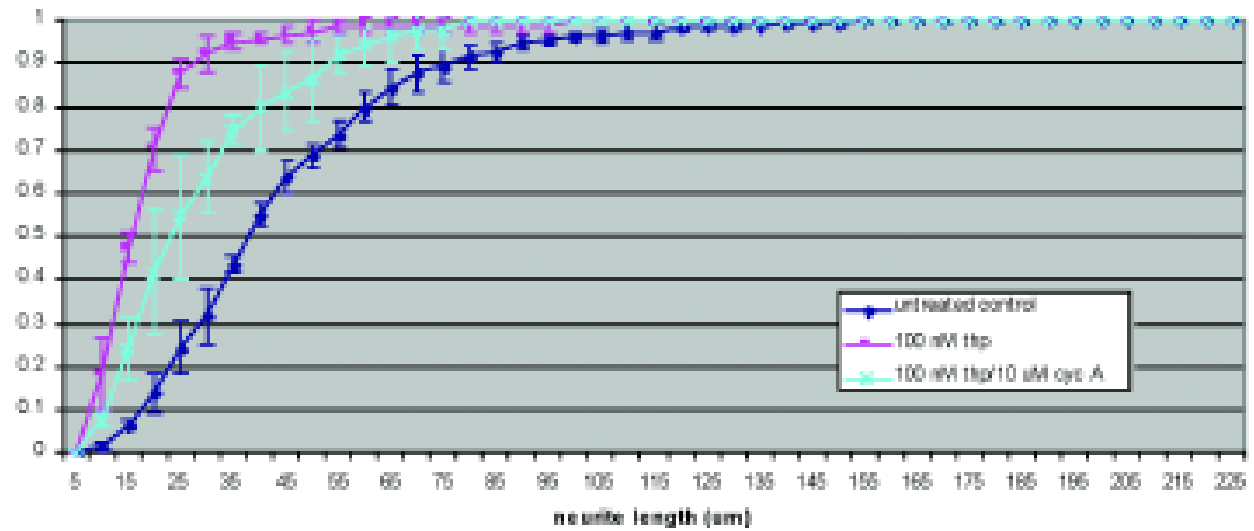

FIG. 2. Graph showing neurite length after a 60-hour incubation with $10 \mu \mathrm{M}$ cyclosporin A. Treatment with $100 \mathrm{nM}$ thapsigargin was used to induce pharmacological injury in the differentiated SH-SY5Y cells.

\section{Neurite Length with 10 nM FK506 after 60 hours}

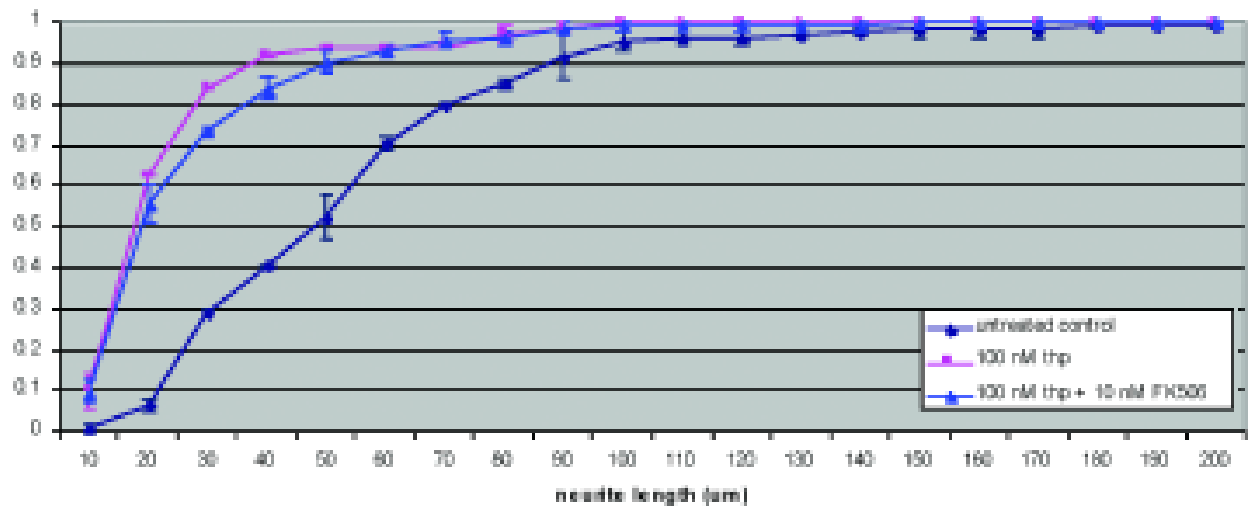

FIG. 3. Graph showing that neurite length in thapsigargin-injured SH-SY5Y cells was increased at the 60-hour time point with the addition of $10 \mathrm{nM}$ FK506. 


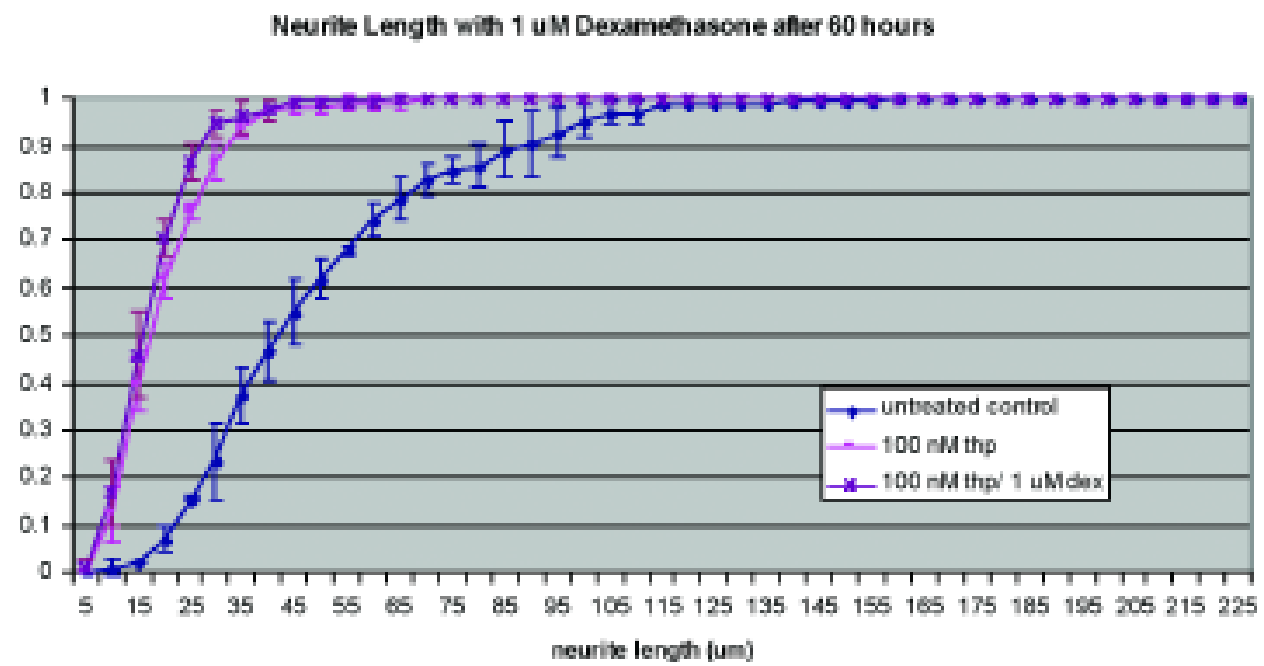

FIG. 4. Graph showing cumulative neurite fraction in thapsigargin-injured SH-SY5Y cells with and without $1 \mu \mathrm{M}$ dexamethasone (dex) treatment.

alone (Fig. 4), although this difference in neurite distribution did not achieve statistical significance. However, addition of $10 \mu \mathrm{M}$ dexamethasone increased the fraction of neurites whose lengths were less than or equal to 10 , $15,20,25,30,35,40$, and 45 microns (Fig. 5) in a statistically significant fashion $(\mathrm{p}<0.05$, t-test).

A qualitative depiction of untreated SH-SY5Y neurite length is depicted in Fig. 6, whereas Fig. 7 illustrates the dramatic reduction in neurite length following 100-nM thapsigargin injury. Figure 8 shows the neurite recovery exhibited by cells treated with $10 \mu \mathrm{M}$ dexamethasone despite thapsigargin injury.

\section{Apoptosis Response}

Depending on the incubation time, $100 \mathrm{nM}$ thapsigargin induced between a 4 and $11 \%$ rate of apoptosis. Treatment of SH-SY5Y cells with $1 \mu \mathrm{M}$ cyclosporin A or $20 \mu \mathrm{M}$ dexamethasone was able to reduce the rates of apoptosis significantly at 36 hours after the thapsigargin insult $(\mathrm{p}<$ 0.05, t-test; Fig. 9).

\section{Discussion}

Human neurons are exquisitely sensitive to cellular perturbations and injury. The first sign that immunosuppressive medications were of use following neuronal injury came from studies of methylprednisolone administered after spinal cord injury. ${ }^{2,4,28}$ Since then, immunosuppressive agents have been a focus of investigation for spinal cord injury, stroke, and neurodegenerative disease. ${ }^{9,15,26}$

Injury to these postmitotic cells can have grave clinical ramifications in such events as stroke, spinal cord injury, and neurodegeneration. Following onset of the aforementioned conditions, intracellular calcium increases have been linked to neuronal injury and cell death. ${ }^{10,18,22}$ The regu-

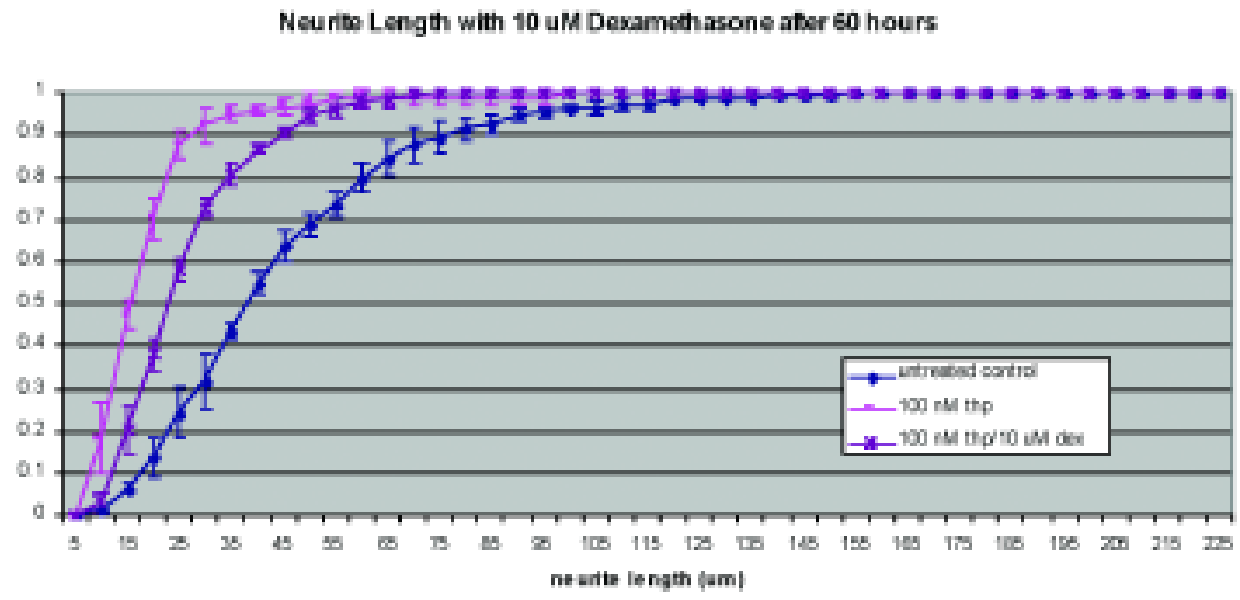

FIG. 5. Graph showing cumulative neurite length in thapsigargin-injured SH-SY5Y cells with and without $10 \mu \mathrm{M}$ dexamethasone treatment. 


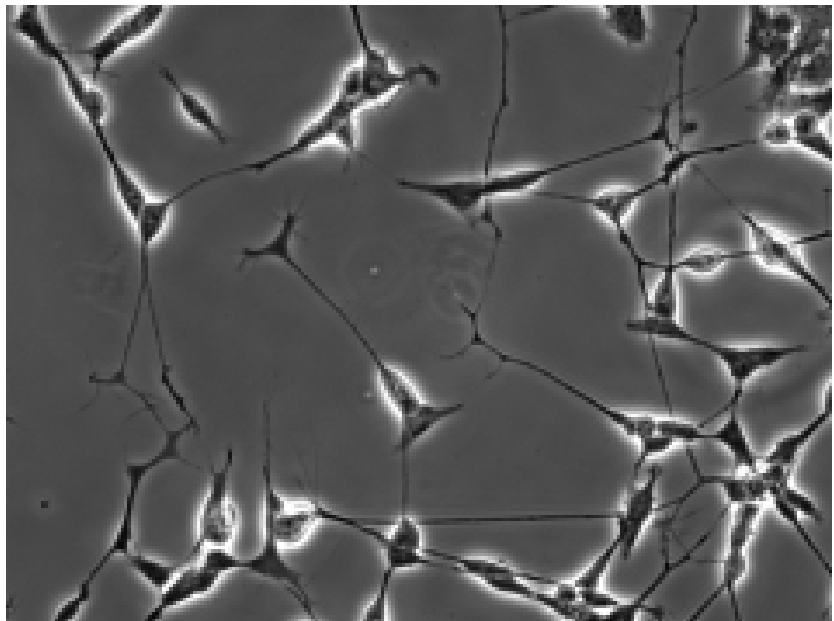

FIG. 6. A phase-contrast photomicrograph of uninjured SHSY5Y cells depicting extensive neurite lengths. Original magnification $\times 20$.

lation of neuronal calcium homeostasis can be achieved by various methods, and immunosuppressive drugs represent one such class of agents that can help lessen the severity of a calcium insult.

The ability to protect neurons and reestablish connections has also been the focus of much investigation. Immunosuppressive agents have been found to be neuroprotective; for example, FK506 and cyclosporin A were found to inhibit calcineurin and suppress caspase activity in SH-SY5Y cells following thapsigargin challenges. ${ }^{17}$ The agent FK506 has also been shown to potentiate nerve growth factor-induced neurite outgrowth in SH-SY5Y cells, in PC12 cells, and in sensory neuronal cultures. ${ }^{11,20,24}$ Our results indicate that FK506, cyclosporin A, and dexamethasone all can promote neurite outgrowth following thapsigargin-induced calcium challenges, and that they can do so without the presence of neurotrophins. Dexamethasone and cyclosporin A can also lessen the extent of apoptosis after thapsigargin-induced injury. Moreover, the

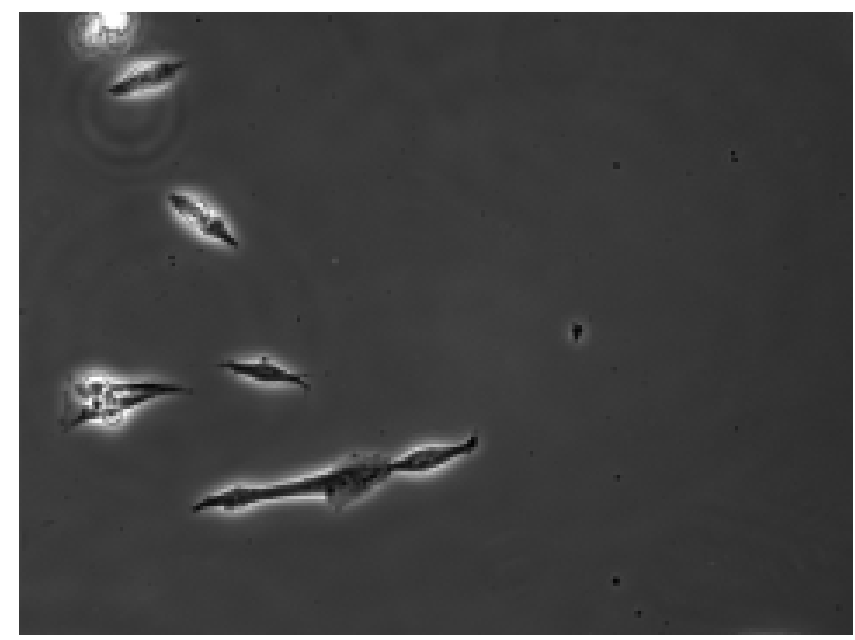

FIG. 7. A phase-contrast photomicrograph illustrating the dramatic reduction in SH-SY5Y neurite length following thapsigargin injury. Original magnification $\times 20$.

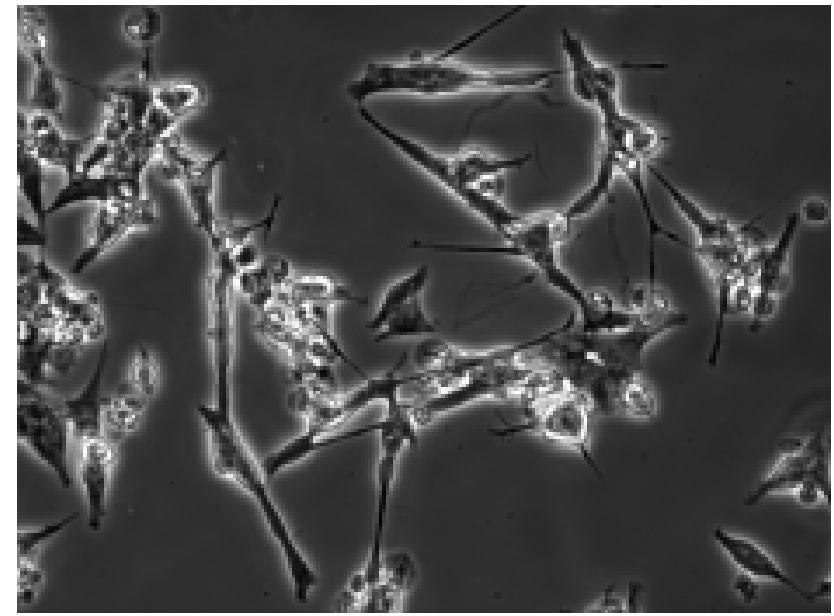

FIG. 8. A phase-contrast photomicrograph showing the improvement in neurite length of SH-SY5Y cells in the presence of both $10 \mu \mathrm{M}$ dexamethasone and $100 \mathrm{nM}$ thapsigargin. Original magnification $\times 20$.

demonstration of in vitro neurite potentiation and antiapoptotic effects of these agents in the absence of immune cells clearly indicates that these changes occur through signal transduction rather than indirect effects on the immune system. It will be important to study these agents in animal models, for better observation of their effects.

The role of immunosuppressive agents is not limited to neuronal protection after injury; these agents have also been used in human neuronal transplantation.,12,13,21,29 Avramut, et al., ${ }^{1}$ demonstrated that FK506 increased neuronal numbers and expression of the neuronal marker MAP2 in human fetal brain cultures. Trojanowski, et al., ${ }^{25}$ reported that cyclosporin prolonged survival of human neuronal cells after transplantation. Based on our in vitro results, appropriate concentrations of FK506, cyclosporin $\mathrm{A}$, and dexamethasone may be used to enhance the neuritic processes of human neuronal cells after transplantation. Such neurite extension may help to integrate the transplanted cells into damaged neuronal circuitry.

Although there is unlikely to be a single agent that will facilitate neuronal protection and potentiate neurite outgrowth in all cases, immunosuppressive agents such as FK506, cyclosporin A, and dexamethasone may play a significant role in pharmacological treatment after neuronal injury. Because all three work on different cellular effectors, a combination of these agents may afford greater neurite outgrowth than any one of them alone. In addition, the in vivo effects of these immunosuppressive agents must be studied in animal models of brain and spine injury and neurodegeneration. Investigators in our laboratory have begun additional research along these lines.

\section{Conclusions}

After pharmacological injury with thapsigargin, the neurite length in differentiated SH-SY5Y cells is severely reduced, and cells undergo a greater rate of apoptosis. Addition of FK506, dexamethasone, and cyclosporin A can significantly potentiate the growth of neurites and protect 


\section{Fraction apoptotic cells as function of time}

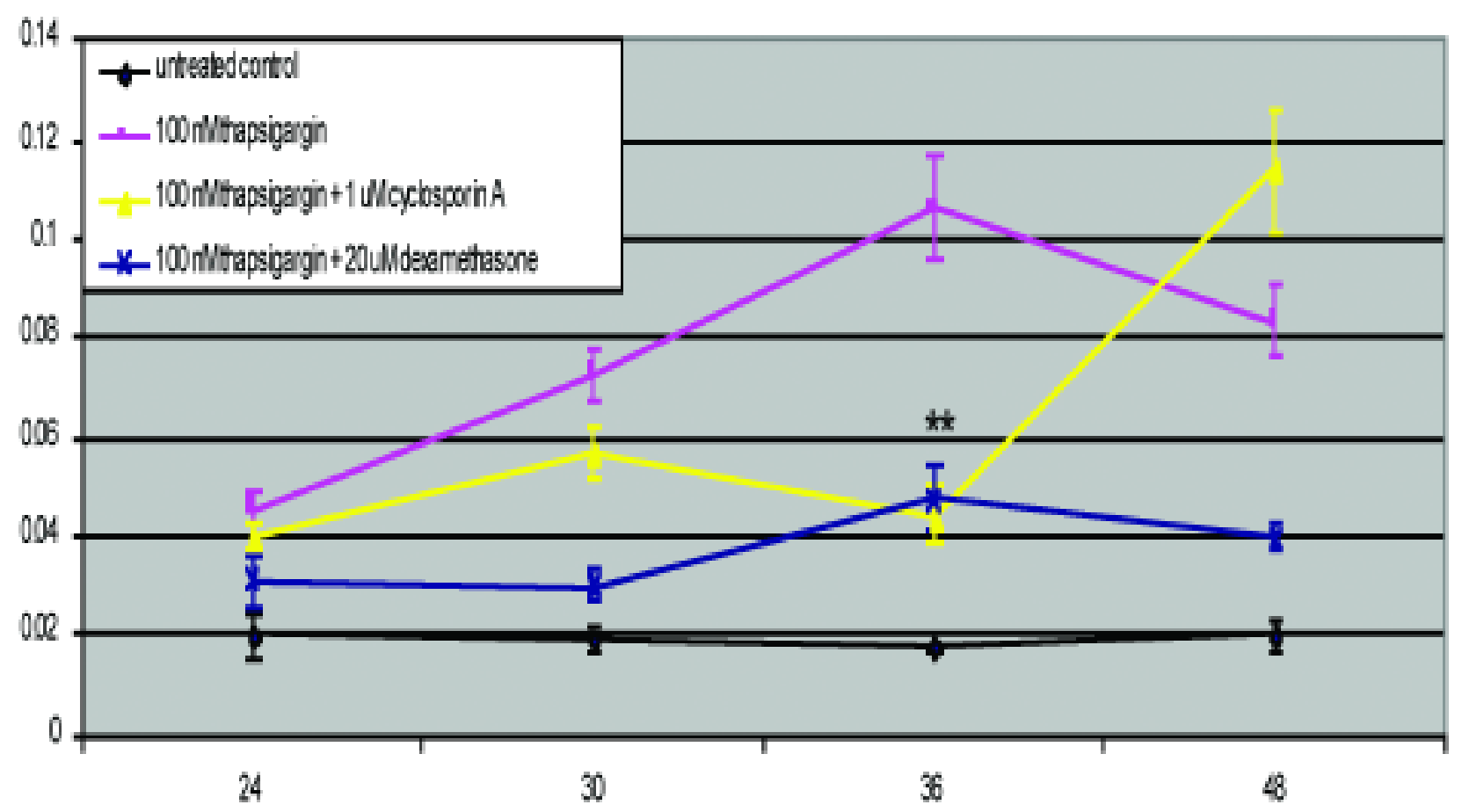

time(hours)

FIG. 9. Graph showing results of a terminal deoxynucleotidyl transferase-mediated deoxyuridine triphosphate nickend labeling assay performed to determine the extent of apoptosis after thapsigargin injury of SH-SY5Y neuronal cells. Double asterisk denotes statistical significance. The values on the y axis represent the fraction of apoptotic cells (number of apoptotic cells divided by the total number of cells).

against apoptosis after calcium agonist injury. The ability to rescue neurites and prevent cell death with immunosuppressive agents alone points to potential therapeutic options for brain and spinal injury, neurodegenerative diseases, and neuronal transplantation.

\section{References}

1. Avramut M, Zeevi A, Achim CL: The immunosuppressant drug FK506 is a potent trophic agent for human fetal neurons. Brain Res Dev Brain Res 132:151-157, 2001

2. Bracken MB: Pharmacological interventions for acute spinal cord injury. Cochrane Database Syst Rev (2):CD001046, 2000

3. Brailoiu E, Hoard JL, Filipeanu CM, Brailoiu GC, Dun SL, Patel S, et al: Nicotinic acid adenine dinucleotide phosphate potentiates neurite outgrowth. J Biol Chem 280:5646-5650, 2005

4. Braughler JM, Hall ED: Current application of "high-dose" steroid therapy for CNS injury. A pharmacological perspective. J Neurosurg 62:806-810, 1985

5. Bultynck G, De Smet P, Weidema AF, Ver Heyen M, Maes K, Callewaert G, et al: Effects of the immunosuppressant FK506 on intracellular $\mathrm{Ca} 2+$ release and $\mathrm{Ca} 2+$ accumulation mechanisms. J Physiol 525:681-693, 2000

6. Cameron AM, Steiner JP, Sabatini DM, Kaplin AI, Walensky LD, Snyder SH: Immunophilin FK506 binding protein associated with inositol 1, 4, 5-trisphosphate receptor modulates calcium flux. Proc Natl Acad Sci U S A 92:1784-1788, 1995
7. Clausen T, Bullock R: Medical treatment and neuroprotection in traumatic brain injury. Curr Pharm Des 7:1517-1532, 2001

8. Dubinsky JM, Brustovetsky N, Pinelis V, Kristal BS, Herman C, Li X: The mitochondrial permeability transition: the brain's point of view. Biochem Soc Symp 66:75-84, 1999

9. Frantseva M, Perez Velazquez JL, Tonkikh A, Adamchik Y, Carlen PL: Neurotrauma/neurodegeneration and mitochondrial dysfunction. Prog Brain Res 137:171-176, 2002

10. Garavito-Aguilar ZV, Recio-Pinto E, Corrales AV, Zhang J, Blanck TJ, Xu F: Differential thapsigargin-sensitivities and interaction of $\mathrm{Ca} 2+$ stores in human SH-SY5Y neuroblastoma cells. Brain Res 1011:177-186, 2004

11. Kano Y, Hiragami F, Kawamura K, Kimata Y, Nakagiri S, Poffenberger CK, et al: Immunosuppressant FK506 induces sustained activation of MAP kinase and promotes neurite outgrowth in PC12 mutant cells incapable of differentiating. Cell Struct Funct 27:393-398, 2002

12. Kondziolka D, Sheehan J, Niranjan A: Ex vivo gene therapy and cell therapy for stroke, in Freese A, Simeone FA, Leone P, Janson C (eds): Principles of Molecular Neurosurgery. Progress in Neurological Surgery, Vol 18. Basel: Karger, 2005, pp 439-457

13. Kondziolka D, Steinberg GK, Wechsler L, Meltzer CC, Elder E, Gebel J, et al: Neurotransplantation for patients with subcortical motor stroke: a phase 2 randomized trial. J Neurosurg 103: 38-45, 2005

14. Macaya A, Munell F, Ferrer I, de Torres C, Reventos J: Cell death and associated c-jun induction in perinatal hypoxia-ischemia. Effect of the neuroprotective drug dexamethasone. Brain Res Mol Brain Res 56:29-37, 1998 
15. Macleod MR, O'Collins T, Horky LL, Howells DW, Donnan GA: Systematic review and metaanalysis of the efficacy of FK506 in experimental stroke. J Cereb Blood Flow Metab 25:713-721, 2005

16. Movsesyan VA, Yakovlev AG, Fan L, Faden AI: Effect of serine protease inhibitors on posttraumatic brain injury and neuronal apoptosis. Exp Neurol 167:366-375, 2001

17. Muramoto M, Yamazaki T, Nishimura S, Kita Y: Detailed in vitro pharmacological analysis of FK506-induced neuroprotection. Neuropharmacology 45:394-403, 2003

18. Nguyen HN, Wang C, Perry DC: Depletion of intracellular calcium stores is toxic to SH-SY5Y neuronal cells. Brain Res 924:159-166, 2002

19. Pahlman S, Mamaeva S, Meyerson G, Mattsson ME, Bjelfman C, Ortoft E, et al: Human neuroblastoma cells in culture: a model for neuronal cell differentiation and function. Acta Physiol Scand Suppl 592:25-37, 1990

20. Price RD, Yamaji T, Matsuoka N: FK506 potentiates NGFinduced neurite outgrowth via the Ras/Raf/MAP kinase pathway. Br J Pharmacol 140:825-829, 2003

21. Sanchez-Pernaute R, Studer L, Ferrari D, Perrier A, Lee H, Viñuela A, et al: Long-term survival of dopamine neurons derived from parthenogenetic primate embryonic stem cells (cyno-1) after transplantation. Stem Cells 23:914-922, 2005

22. Sheehan JP, Swerdlow RH, Parker WD, Miller SW, Davis RE, Tuttle JB: Altered calcium homeostasis in cells transformed by mitochondria from individuals with Parkinson's disease. J Neurochem 68:1221-1233, 1997

23. Shen Y, Li R, Shiosaki K: Inhibition of p75 tumor necrosis factor receptor by antisense oligonucleotides increases hypoxic injury and beta-amyloid toxicity in human neuronal cell line. $\mathbf{J}$ Biol Chem 272:3550-3553, 1997
24. Steiner JP, Hamilton GS, Ross DT, Valentine HL, Guo H, Connolly MA, et al: Neurotrophic immunophilin ligands stimulate structural and functional recovery in neurodegenerative animal models. Proc Natl Acad Sci U S A 94:2019-2024, 1997

25. Trojanowski JQ, Mantione JR, Lee JH, Seid DP, You T, Inge LJ, et al: Neurons derived from a human teratocarcinoma cell line establish molecular and structural polarity following transplantation into the rodent brain. Exp Neurol 122:283-294, 1993

26. Vink R, Nimmo AJ, Cernak I: An overview of new and novel pharmacotherapies for use in traumatic brain injury. Clin Exp Pharmacol Physiol 28:919-921, 2001

27. Yang JT, Lee TH, Weng HH, Chang CN, Chen WC, Cheng WC, et al: Dexamethasone enhances NT-3 expression in rat hippocampus after traumatic brain injury. Exp Neurol 192: 437-443, 2005

28. Young W: Secondary injury mechanisms in acute spinal cord injury. J Emerg Med 11 Suppl 1:13-22, 1993

29. Zhang C, Saatman KE, Royo NC, Soltesz KM, Millard M, Schouten JW, et al: Delayed transplantation of human neurons following brain injury in rats: a long-term graft survival and behavior study. J Neurotrauma 22:1456-1474, 2005

Manuscript received January 13, 2006.

Accepted in final form April 11, 2006.

This work was funded in part by a grant from the Virginia Commonwealth Neurotrauma Initiative.

Address reprint requests to: Jason Sheehan, M.D, Ph.D, Department of Neurological Surgery, University of Virginia Health System, Box 800-212, Charlottesville, Virginia 22908. email: jps2f@virginia.edu. 